\title{
Intelligent Learning Systems for Cognitive Skills Development
}

\author{
Kinshuk \\ Massey University, New Zealand
}

kinshuk@massey.ac.nz

\begin{abstract}
This tutorial deals with the broad class of intelligent learning systems for cognitive skills development. These systems have proved very effective, especially within the applied domains where learning is more concerned with the operational knowledge. These systems can accommodate both the 'instruction' and 'construction' of knowledge and involve active engagement, they have been more successful as demonstrated by the popularity and wide acceptance of simulation based learning systems. This tutorial aims to provide the intelligent systems developer and implementer community with the knowledge that they need in order to make informed assessments and decisions about such systems. It considers in turn five questions that can be asked about any intelligent learning systems for cognitive skills development: 1. What are the various aspects of learning facilitated by such systems? 2. What are the theoretical issues that underlie development of such systems? 3. What functions are served by intelligence and how they are twinned with assessment issues? 4. What pedagogical issues are important in the development of such systems? 5. How one can go about practically developing such systems?
\end{abstract}

Keywords: Cognitive skills, Intelligent tutoring, Cognitive apprenticeship.

\section{Introduction}

Domain competence for any discipline consists of both domain knowledge and subject related skills, though analytical disciplines (such as philosophy, economics and so on) have major focus on domain knowledge whereas task oriented disciplines (such as medicine, engineering and so on) rely more on skill based competence. The skill based competence embeds two ingredients: physical skills, which constitute physical expertise of domain, related to the procedural tasks; and cognitive skills, which are the skills to "carry out" procedural tasks of the domain, thus have more to do with analysis, interpretation and decision making processes.

Although both physical and cognitive skills demand a great deal of training and practice to achieve competence, physical skills are easier to obtain due to their external visibility in carrying out the processes and tasks. It is possible for the students to visualise the processes and learn through

Material published as part of this proceedings, either on-line or in print, is copyrighted by the author with permission granted to the publisher of Informing Science for this printing. Permission to make digital or paper copy of part or all of these works for personal or classroom use is granted without fee provided that the copies are not made or distributed for profit or commercial advantage AND that copies 1) bear this notice in full and 2) give the full citation on the first page. It is permissible to abstract these works so long as credit is given. To copy in all other cases or to republish or to post on a server or to redistribute to lists requires specific permission from the author. observations. On the other hand, cognitive skills demand a more sophisticated learning process to acquire the experience in handling cognitive tasks. Much of the processes involved in cognitive skills run inside human mind and therefore, are not visible. Hence it is difficult to acquire such skills compared to physical skills.

For example, entering the data in a spreadsheet in short time with less mistakes requires physical skills which can be obtained by observing a master's eye and hand coordinations and other physical movements, but the interpretation of that data to find out the validity of the underlying conceptual rules requires mental exercise and can be attributed to cognitive skills. Applied disciplines often require application of cognitive skills in real life situations.

This tutorial is mainly concerned with applied disciplines. The major part of learning in applied disciplines concerns with the application of cognitive skills in applying conceptual relationships of the disciplines to solve problems. The learners need to acquire a sense of judgement and decision making skills of the discipline in different contexts. They require to have different skills related to analysis, methodical approach, identification and solution of intermediate steps, and systematic build up of the full solution. 
Kinshuk

The tutorial discusses the deficiency of current academic practices in providing adequate cognitive skills to the learners since these practices tend to focus more on the theoretical domain knowledge and mechanical procedural skills and hence leaving the learners unable to apply their competence in real world situations. The tutorial, in this context, reviews the inherent problems in acquiring cognitive skills and describes two projects that attempted to provide solutions.

\section{Byzantium Architecture}

As a possible solution towards achievement of adequate domain competence for numeric task oriented disciplines, an intelligent tutoring environment (ITE) is designed under Byzantium project. The project adopts cognitive apprenticeship framework (Collins, Brown \& Newman, 1989) since cognitive apprenticeship framework aims to provide adequate domain competence to the learner while focusing on cognitive skills. The Byzantium ITE subsequently has major focus on the facilitation of cognitive skills, though it also provides physical skills and basic domain knowledge. The ITE has been applied and evaluated in four intelligent tutoring modules of cost engineering discipline (namely capital investment appraisal, absorption costing, marginal costing and standard costing). The structure and functionality of these modules have been described in Patel \& Kinshuk (1997). This paper describes the implementation of cognitive apprenticeship in the Byzantium ITE through representing suitable granularity over the interface and providing guidance to the learner at various levels of learner-system interaction.

The Byzantium intelligent tutoring environment (ITE) is primarily aimed for numeric disciplines, which are task oriented and require the learners to achieve cognitive skills as a major constituent of domain competence besides concepts and physical skills. The environment adopts cognitive apprenticeship framework in its architecture and supports following main tasks in learning:

a) Observation - for acquisition of the concepts

b) Simple imitation - skills acquisition through articulation of the concepts

c) Advanced imitation - for generalisation and abstraction of already acquired concepts and for acquisition of skills of applying concepts in different contexts

d) Contextual observation - for deeper learning after imitation process results into the identification of gaps in learner's current understanding of the domain knowledge e) Interpretation of real life problems - for acquiring competence in such narrative problems as encountered in real life situations

f) Mastery in skills - for repetitive training

g) Assessment - for measurement of overall progress

The environment operates in three main phases:

i) basic concepts observation phase, which supports above mentioned task (a);

ii) interactive skills acquisition phase, which supports tasks (b) to (f); and

iii) assessment phase, which supports task (g).

The basic concepts observation phase aims to provide the observation of the conceptual knowledge and the procedural tasks of the discipline with the help of multimedia and hypermedia techniques. The interactive skills acquisition phase aims to provide acquisition of skills by presenting the non-contextual and contextual problems of the discipline with the help of multi-granular interfaces. The assessment phase aims to assess the overall progress of the learners' domain competence. The interactive skills acquisition and assessment phases are similar in structure except that there is no immediate feedback in assessment phase as opposed to interactive skills acquisition phase where system guidance is available at all stages of learning.

An important aspect in the cognitive skills acquisition is to provide the learners with proper problems of the domain. Schank \& Cleary (1995) demonstrated that too frequently inadequate attention is given to the design of problems. The Byzantium ITE considered this issue seriously and as a result, domain problems are provided to the learners from four different sources adequate to different stages of learning:

a) Teacher generated non-contextual problems: for noncontextual learning

b) Teacher generated contextual problems: for noncontextual to contextual transition and contextual learning

c) Randomly generated problems: for repetitive training

d) Narrative problems for interpretation skills acquisition: for contextual learning and transition from contextual to real life problems

The recommended learning path consists of sequential traverse through observation, simple imitation, advanced imitation and interpretation of real life problems stages before the learners attempt to acquire the mastery in skills and assess the overall progress of domain competence. But 


\section{Intelligent Systems for Cognitive Skills}

this learning path is not mandatory and the learners can explicitly choose any of the stages of learning and can switch to other stages as and when felt necessary. There are some restrictions, though, such as, assessment stage can be left only either after completion of assessment or by abandoning current assessment problem, because it would not be a fair assessment if the learners could go to observation stage in the middle of overall assessment.

\section{InterSim Architecture}

Another project aimed to provide cognitive skills is the InterSim project, which provided an educational multimedia system that can be used in and outside educational institutions an is suitable where the constraints of space, time or resources limit the possibility of regular institutional access. It may be combined with other means of education to suit different learning environments such as classroom based, open, and distance learning. The system facilitates competence not only in domain knowledge but also in related cognitive skills that are difficult to obtain in absence of 'hands-on' training in real working environment. The learning environment follows the cognitive apprenticeship model (Collins, Brown \& Newman, 1989) that fulfils the requirements of both academic and situated learning. The system is activity oriented and supports acquisition of cognitive competence in both knowledge and task oriented performances. It should be noted that interpretations and decision making are also regarded as activities. The following are the characteristics of the learning environment.

Modelling: In this environment, the learners can study the task solving patterns of experts to develop their own cognitive model of the domain as related to the tasks, tools and solutions. The technical support provides guided tours (demonstrations and simulations) and textual explanations. The learners can work with the tutorials and perform interactive imitations of the demonstrated simulations.

Coaching: The environment allows the learners to solve tasks on their own by consulting a tutorial component.

The technical support provides exploration tools for the learners to search for possible solutions, try them out and to solve any attendant problems. The technical support also provides consultation facilities for solving notorious errors.
Fading: The environment's tutoring activity is gradually reduced in line with a learner's improving performance and problem solving competence.

The technical support provides a learner with adapted intelligent assistance in the form of recommendations and support throughout the learning process. Such assistance is based on the learner's progress in understanding the subject matter and thus the novice learners are provided with a much higher level of assistance.

The InterSim system, incorporating the above learning environment, is beneficial with respect to various sociotechnical factors. The system provides a risk free simulated environment for explorations by a learner without the fear of harming a fellow human and includes real world scenarios based on actual patients. Such systems are applicable to a wide geographic area, since multimedia techniques facilitate the adoption of multilingual support with little effort. After the initial prototyping investments, systems based on the InterSim approach are likely to prove economically viable as they offer immediate savings in terms of human and laboratory resources and a longer life cycle due to well established domains and low rate of subject matter obsolescence.

The InterSim system provides learning according to the demands of the domain, for example, the ear domain requires a deep understanding of the structural and functional aspects so the learning strategies emphasise visual and spatial learning aids. Since the exploratory learning approaches (simulation based) are implemented in combination with the logical approaches (rule based path determination towards the solution), the learning in the InterSim system is based both on learning by doing and learning from other's experiences. The system can be set by a user into three main functional states:

1. The Learning State enables access to all the learning contents of the system and provides immediate (dynamic) feedback on user actions with a view to facilitate active learning.

2. The Assessment State is for testing a learner's learning and retention of the domain knowledge and skills. The system allows a learner to make mistakes and provides a delayed (static) feedback after the work is assessed.

As Routen (1992) observed,

"There are advantages with both forms of student monitoring. Static feedback perhaps is less obtrusive ... 
while dynamic feedback prevents students from making gross errors and getting completely lost."

3. The Case Authoring State provides authoring facilities to doctors and teachers for adding real life cases to the system.

\section{Conclusion}

The acquisition of cognitive skills is not only an essential art in domain competence, it is rather difficult in the absence of human expert. Intelligent learning environments, which are specifically focused on cognitive skills, can make a huge difference in such scenario and can be particularly useful in life-long learning and other similar learning situations lacking direct interaction between learner and the teacher. This tutorial discussed the need of such environments and presented two projects where such intelligent learning environments are developed.

\section{References}

Collins A., Brown J. S. \& Newman S. E. (1989). Cognitive Apprenticeship : Teaching the crafts of reading, writing and mathematics. In Lauren B. Resnick (Ed.) Knowing, Learning and Instruction, Hillsdale, N. J.: Lawrence Erlbaum Associates, 453-494.
Patel A. \& Kinshuk (1997). Intelligent Tutoring Tools in a Computer Integrated Learning Environment for introductory numeric disciplines. Innovations in Education and Training International Journal, 34 (3), 200-207.

Schank R. Cleary C. (1995). Engines for Education. Technical Report No. 58, http://www.1ls.nwu.edu/ e_for_e/1ndex.htm,

Routen T. (1992). Reusing formalisations of legislation in a tutoring system. Artificial Intelligence Review, 6, 145-159.

\section{Biography}

Kinshuk is Senior Lecturer at the Massey University, New Zealand. He has been involved in large scale research and development projects for cognitive skills based adaptive educational environments and has published over 50 research papers in international refereed journals, conferences and book chapters. He is an active researcher in learning technologies and human computer interactions. $\mathrm{He}$ is currently chairing IEEE Learning Technology Task Force, New Zealand chapter of ACM SIGCHI, Manawatu Information Technology Cluster and the International Forum of Educational Technology \& Society. He is also editor of 'Educational Technology \& Society' journal (ISSN 1436-4522) and 'Learning Technology Newsletter (ISSN 1438-0625). 